\title{
Effect of tobacco smoke on the growth, biochemical composition, and biodiesel characteristics of two Chlamydomonas strains
}

\section{Bahram Barati}

School of Energy and Power Engineering, Jiangsu University, Jiangsu, 212013, China

Fatemeh Fazeli Zafar

School of Energy and Power Engineering, Jiangsu University, Jiangsu, 212013, China

Shuang Wang ( $\sim$ alexjuven@ujs.edu.cn )

School of Energy and Power Engineering, Jiangsu University, Jiangsu, 212013, China

\section{Abd El-Fatah Abomohra}

Department of Environmental Engineering, School of Architecture and Civil Engineering, Chengdu University, Chengdu 610106, China

\section{Research Article}

Keywords: Chlamydomonas, Growth, Biodiesel, Fatty acids, Smoke effect

Posted Date: August 11th, 2021

DOl: https://doi.org/10.21203/rs.3.rs-800439/v1

License: (9) This work is licensed under a Creative Commons Attribution 4.0 International License. Read Full License 


\section{Abstract}

Microalgae has been known as one of the efficient biological carbon dioxide $\left(\mathrm{CO}_{2}\right)$ sequesters. In recent years, they have been applied to improve the air quality by reducing $\mathrm{CO}_{2}$ concentration and boosting oxygen $\left(\mathrm{O}_{2}\right)$ level, and have the ability to tolerate diverse toxic elements in the air. The current study investigates the effect of tobacco smoke on the growth, biochemical, and biodiesel characteristics of two Chlamydomonas strains. For this purpose, strains were exposed to seven days of tobacco smoke by burning one cigarette per hour in a closed box containing the air supply. CHL-2220 continued its proliferation without demonstrating any inhibition, while the growth of the other strain (CHL-2221) was inhibited severely. Tobacco smoke significantly altered the biochemical composition of CHL-2221, and caused the accumulation of more carotenoids and carbohydrates as part of the stress response. The analyzed biodiesel parameters presented poor quality from the extracted lipid of both strains. However, the fatty acid profile of the studied strain demonstrated their promising application as nutrient food supplements and feed for animals.

\section{Introduction}

According to the World Health Organization (WHO), air pollution and human exposure to low-quality air are the most critical environmental threats to the public [1]. Particularly, indoor air pollution has become more apparent in recent years, as people spend more than $80 \%$ of their time indoors, and buildings are progressively sealed to obtain heating and cooling energy savings [2]. The most common types of indoor air pollutants such as particulate matter (dust, smoke, and biomass), bioaerosols (molds, spores), and gaseous contaminants (nitrogen dioxide, carbon monoxide, sulfur dioxide, ozone, formaldehyde, and volatile organic compounds) derived from building product emissions, human activity indoor, and infiltration of outdoor air are important contributors to low indoor air quality [3]. Recent studies have shown that low indoor air quality due to increased levels of $\mathrm{CO}_{2}$ is a major contributor to global health problems and causes losses of huge amount of money [4,5]. Microalgae, as photosynthetic organisms with significantly higher photosynthetic efficiency, can be used as biological air purifiers to produce $\mathrm{CO}_{2}$ and reduce toxic elements such as NOx and SOx [6]. Thus, microalgal photobioreactors may be a feasible solution for indoor environments with elevated $\mathrm{CO}_{2}$ levels, such as offices, schools, or shopping centers [7]. Therefore, the application of microalgae as air purifiers has been attracted attention in recent years $[8,9]$.

In these systems, not only during the growth of microalgae $\mathrm{CO}_{2}$ can be converted to $\mathrm{O}_{2}$, but the produced biomass can be exploited to produce various biofuels [10,11], as achieving cost-effective, eco-friendly fuels, and renewable energy sources have been considered one of the significant challenges of the twenty-first century [12]. Microalgae can accumulate as high as $30-70 \%$ of lipids of their cellular dry weight [13]. The lipids extracted from microalgal biomass can be utilized for biodiesel production through chemical conversion via transesterification [14]. This is due to the high lipid productivity of microalgae compared to other biodiesel feedstocks, the absence of competition with human food, and their potential 
to grow on marginal and non-arable land [15]. Moreover, it is known that microalgae can accumulate high levels of poly unsaturated fatty acids (PUFAs), which are important components playing a significant role in human and animal health and development [16]. Also, the lipid extracted residual biomass of lipid microalgae can be utilized as a potential source of feed protein for animals, fish, crab and shrimp $[17,18]$.

Tobacco smoke is one of the indoor air pollutants that is increasing day by day, and contains chemical substances that most of them are carcinogenic, mutagenic, irritating, or toxic [19]. Although the response of various toxic air pollutants such as $\mathrm{NO}_{x} \mathrm{SO}_{x}$ and $\mathrm{CO}_{2}$ have been studied in microalgae [20], no study has investigated the effect of tobacco smoke on microalgal growth and biochemical composition to date. Despite the presence of smoking rooms in public places, tobacco smoke leakage from smoking rooms has been observed [21]. Therefore, if biological air purifiers in public places such as train stations, airports, and hotels are used, it is necessary to evaluate tobacco smokes' effect on microalgae. Chlamydomonas sp. is considered as an incredible model organism among different algal species to comprehend and boost biofuels' production in algae, probably due to progress in molecular tools to select green algal strains and engineering, and for its diverse potential applications [22]. Thus, in this study, the effects of tobacco smoke on growth and its biochemical compositions of the model microalga, Chlamydomonas sp. were studied. Also, its potential use as biodiesel feedstock was evaluated to determine two strains of tobacco smoke's exact behavior and the possibility to be used for biodiesel production.

\section{Materials And Methods}

\subsection{Culture condition and experimental design}

Two Chlamydomonas strains (FACHB-2220 and FACHB-2221) were purchased from the Freshwater Algae Culture Collection at the Institute of Hydrobiology (FACHB), Wuhan, China, represented in this study as CHL-2220 and CHL-2221, respectively. The stock culture was grown in tris-acetate-phosphate (TAP) medium and maintained in ambient temperature and light prior to the experiment. To prepare $20 \%$ inoculum, $100 \mathrm{ml}$ of culture standardized at $\mathrm{OD}_{750}=0.2$ were added to $400 \mathrm{~mL}$ sterilized medium in an Erlenmeyer flask. The cultures were incubated at $25 \pm 1.5^{\circ} \mathrm{C}$, and illuminated with white fluorescent lamps at a light intensity of $50 \mu \mathrm{mol}$ photons $\mathrm{m}^{-2} \mathrm{~s}^{-1}$ and 12:12 $\mathrm{h}$ light-dark cycle. The cultures were aerated using an air pump placed in a closed box. To study the effect of cigarette smoke, one cigarette was flamed, and placed in the box to feed concentrated tobacco smoke into the cultures. The treated samples were aerated with the smoke of one cigarette per hour. The maximum specific growth rate was determined according to the natural logarithm of optical density $\left(\mathrm{OD}_{750}\right)$ plotted versus time (day) during the exponential growth phase using Eq. (1) [23]:

$\mu_{\max }\left(\right.$ day $\left.^{-1}\right)=\left(\operatorname{Ln} D_{e}-\operatorname{Ln} D_{i}\right) /\left(t_{e}-t_{i}\right)$

where $D_{2}$ is $O D_{750}$ at $t_{e}, D_{i}$ is $O D_{750}$ at $t_{i}$, and $t_{e}$ and $t_{i}$ are times within the exponential phase. In addition, biomass productivities $(\mathrm{P})$ were determined from the differences in biomass throughout the cultivation 
time as shown in Eq. (2) [24]:

$\mathrm{P}\left(\mathrm{g} \mathrm{DW} \mathrm{L} \mathrm{L}^{-1} \mathrm{~d}^{-1}\right)=\left(X_{f} X_{i}\right) /\left(t_{f} t_{i}\right)$

where $\mathrm{X}_{\mathrm{f}}$ is the dry weight (in $\mathrm{g} \mathrm{DW} \mathrm{L}^{-1}$ ) at times, $\mathrm{t}_{\mathrm{f}}$ and $X_{i}$ is the dry weight at $\mathrm{t}_{\mathrm{i}}$ (in days), representing the final and initial time of cultivation, respectively.

\subsection{Pigment measurement}

Extraction of chlorophylls and carotenoids was conducted by filtering $20 \mathrm{~mL}$ of the sample on a glassfiber filter (Whatman GF/C, $0.45 \mu \mathrm{m}$ ). The filtered samples were broken with a glass hand homogenizer in a known volume of absolute methanol. The samples were then covered with aluminum foil and incubated in the fridge overnight. Prior to spectrophotometric measurement, the samples were centrifuged at $1409 \times \mathrm{g}$ for $5 \mathrm{~min}$ to obtain the clear supernatant. Chlorophyll concentrations $(\mathrm{mg} / \mathrm{L})$ were determined by measuring the absorbance of cell extracts at 665 and $645 \mathrm{~nm}$ using a UV-vis spectrophotometer according to the Eq. (3) [25]:

Chlorophyll content $\left(\mathrm{C}_{a}+\mathrm{C}_{b}\right)=\left(1.44 \times \mathrm{A}_{665}\right)+\left(24.93 \times \mathrm{A}_{652}\right)(3)$.

Also, carotenoids $(\mathrm{mg} / \mathrm{L})$ were measured in the same supernatant by measuring the absorbance at 470 $\mathrm{nm}$, and the carotenoid concentration was calculated according to Eq. (4) [25]:

Total carotenoid $=\left(1000 \mathrm{~A}_{470}-1.63 \mathrm{C}_{a}-104.96 \mathrm{C}_{b}\right) / 214(4)$.

\subsection{Determination of carbohydrate, protein and lipid content}

Carbohydrate content was determined according to the standard protocol presented by Borowitzka and Moheimani (2013) [26] with slight modification. Briefly, $50 \mathrm{~mL}$ of each replicate was centrifuged, and the pallet was mashed in a hand homogenizer with $\mathrm{HCl}(2 \mathrm{M})$. The homogenized samples were incubated and sonicated for $1 \mathrm{~h}$ in an ultra-sonicator adjusted at $80^{\circ} \mathrm{C}$. Then, after the centrifugation step, aliquots of samples were added, followed by water, phenol and $\mathrm{H}_{2} \mathrm{SO}_{4}(95.5 \% \mathrm{v} / \mathrm{v})$. After incubation for 30 minutes, the optical density was measured at $485 \mathrm{~nm}\left(\mathrm{OD}_{485}\right)$. The exact concentration of carbohydrates was extrapolated from the standard curve using glucose as a standard reference. Lipids were extracted from stationary phase cultures using methanol/chloroform/water $(2: 1: 0.8 \mathrm{v} / \mathrm{v})$ and determined by the gravimetric method by Bligh and Dyer [27]. The extract was blown with a mild stream of Nitrogen gas, and the dried extract was kept in a desiccator for $24 \mathrm{~h}$ before measuring the weight. The difference in weights was taken as the weight of the lipid extract. Proteins were extracted with $0.5 \mathrm{~N} \mathrm{NaOH}\left(80{ }^{\circ} \mathrm{C}, 30\right.$ min), and the concentration was determined by the dye-binding method [26].

\subsection{Fatty acid analysis}

Lipid transesterification was conducted by adding $1 \mathrm{~mL}$ of $1 \% \mathrm{H}_{2} \mathrm{SO}_{4}-\mathrm{MeOH}$ to the cells and heating up to $90^{\circ} \mathrm{C}$ for $1 \mathrm{~h}$ using a test tube heater. FAMEs were dissolved by hexane and kept after hexane evaporation 
in a freezer at $-20^{\circ} \mathrm{C}$. The extracted FAMEs were subjected to gas chromatography-mass spectrometry (GC/MS, Thermo Fisher Scientific, USA). A non-polar DB 35 column was used, and helium was applied as a carrier gas. A volume of $1 \mu \mathrm{L}$ sample was injected to the GC/MS under a systematic temperature program from an initial oven temperature of $40^{\circ} \mathrm{C}$ at an initial stable time of $5 \mathrm{~min}$, then raised to a final temperature of $260^{\circ} \mathrm{C}$ at a rate of $4^{\circ} \mathrm{C} \mathrm{min}-1$ and held for $1 \mathrm{~min}$.

\subsection{Biodiesel characteristics}

In order to investigate the quality of the produced biodiesel, the physicochemical properties of FAMEs were calculated. The percentage of unsaturation degree (DU, \%), cetane number (CN), iodine value (IV, g $\mathrm{I}_{2} / 100 \mathrm{~g}$ oil), saponification value (SV, $\mathrm{mg} \mathrm{KOH} \mathrm{g}^{-1}$ ), long-chain saturation factor (LCSF, wt\%) and cold filter plugging point $\left(\mathrm{CFPP},{ }^{\circ} \mathrm{C}\right)$ were calculated according to Ramírez-Verduzco et al. [28] and Ashour et al. [29] as shown in Eqs. (5-10);

$\mathrm{DU}=\Sigma[$ MUFAs $+(2 \times$ PUFAs $)](5)$

where, MUFAs and PUFAs represent the percentage of monounsaturated and polyunsaturated fatty acids, respectively.

$S V=\Sigma\left[\left(560 \times N_{\%}\right) / M\right](6)$

$\mathrm{IV}=\Sigma\left[\left(254 \times \mathrm{N}_{\%} \times \mathrm{D}\right) / \mathrm{M}\right](7)$

$\mathrm{CN}=46.3+(5458 / \mathrm{SV})-(0.225 \times \mathrm{IV})(8)$

where, $\mathrm{N} \%$ represents the percentage of each fatty acid; $M$ represents the molecular mass of each fatty acid, and $\mathrm{D}$ represents the number of carbon-carbon double bonds.

$\operatorname{LCSF}=(0.1 \times \mathrm{C} 16: 0)+(0.5 \times \mathrm{C} 18: 0)+(1 \times \mathrm{C} 20: 0)+(1.5 \times \mathrm{C} 22: 0)+(2 \times \mathrm{C} 24: 0)(9)$

CFPP $=(3.1417 \times$ LCSF $)-16.477(10)$

where $\mathrm{C} 16: 0, \mathrm{C} 18: 0, \mathrm{C} 20: 0, \mathrm{C} 22: 0$ and $\mathrm{C} 24: 0$ represent the weight percentage of the corresponding fatty acids. Also, the higher heating value calculated using Eq (11) [30];

$\mathrm{HHV}(\mathrm{MJ} / \mathrm{KG})=49.43-0.015(\mathrm{IV})-0.041(\mathrm{SV})(11)$

\subsection{Data analysis}

Experiments were carried out in three replicates. The effect of tobacco smoke on the lipids, carbohydrates, proteins, pigments, and fatty acids was analyzed using one-way ANOVA. All the statistical analyses were carried out in SPSS 16.0 (SPSS Inc., USA), and the differences were considered significant when $\mathrm{P}<0.05$. 


\section{Result And Discussion}

\subsection{Effect of tobacco smoke on growth}

Growth was studied by monitoring the optical density of the samples grown under tobacco smoke exposure for seven days. As shown in Fig.1, the growth pattern was different between the smoke-exposed culture and ambient. By increasing the exposure time, the difference increased, while CHL-2221 could not tolerate the stress induced by smoke and its growth was significantly lower than the control. Although $\mathrm{CHL}-2220$ exhibited lower growth by day 3 , it could tolerate the introduced smoke, and regain its growth performance by the end of the cultivation time. That is maybe because of microalgal cells' ability to survive under tobacco smoke, but they take time to adapt to adverse conditions.

The specific growth rate and biomass productivity of the studied strains are presented in Table 1. Under the ambient conditions, $\mu_{\text {max }}$ in CHL-2220 and CHL-2221 was 0.506 day $^{-1}$ and 0.445 day $^{-1}$, respectively, indicating a significantly faster growth rate in CHL-2220. The $\mu_{\max }$ was not affected in CHL-2220, and it was approximately 0.500 day $^{-1}$. While in $\mathrm{CHL}-2221, \mu_{\max }$ decreased significantly from 0.445 to 0.376 day $^{-1}$. The biomass productivity of $\mathrm{CHL}-2220$ showed insignificant changes in response to tobacco smoke exposure. However, in CHL-2221, it significantly declined from $0.090 \mathrm{~g} \mathrm{DW} \mathrm{L}^{-1} \mathrm{~d}^{-1}$ to $0.065 \mathrm{~g} \mathrm{DW}^{-}$ $\mathrm{L}^{-1} \mathrm{~d}^{-1}$. Obviously, $\mathrm{CHL}-2220$ exhibited a faster growth rate and biomass productivity in comparison to CHL-2221; thus, it is considered a relatively tolerant strain.

Table 1. Specific growth rate and biomass productivity of CHL-2220 and CHL-2221 under ambient air and tobacco smoke treatment.

\begin{tabular}{|c|c|c|c|c|}
\hline \multirow[t]{2}{*}{ Strains/parameters } & \multicolumn{2}{|l|}{ CHI-2220 } & \multicolumn{2}{|l|}{ CHL-2221 } \\
\hline & Control & Smoke treated & Control & Smoke treated \\
\hline $\begin{array}{l}\text { Specific growth rate } \\
\left(\mu_{\max }, \text { day }^{-1}\right)\end{array}$ & $0.506 \pm 0.027$ & $0.517 \pm 0.071$ & $0.445 \pm 0.053$ & $0.376 \pm 0.050^{\star}$ \\
\hline $\begin{array}{l}\text { Biomass productivity } \\
\left(\mathrm{P}, \mathrm{g} \mathrm{DW} \mathrm{L}^{-1} \mathrm{~d}^{-1}\right)\end{array}$ & $0.097 \pm 0.002$ & $0.099 \pm 0.015$ & $0.090 \pm 0.010$ & $0.065 \pm 0.007 *$ \\
\hline
\end{tabular}

Values are the mean $\pm S D$ of three replicates, while the " $\star$ " denotes to significant difference $(P<0.05)$ with the corresponding control.

\subsection{Effect of tobacco smoke on carotenoids level}

Monitoring photosynthetic pigments such as chlorophyll and carotenoids offers a valuable understanding of cell stress, metabolic flux, and photosynthetic potential [31]. Changes induced by various stressors are initially detectable in photosynthetic pigments changes before the recognition of 
any changes in the growth [32]. Therefore, pigment analysis is broadly applied to understand photosynthetic organism's responses towards stress. The pigment content under different conditions for both microalgae strain are presented in Fig.2. Interestingly, the carotenoid content was not affected in CHL-2220, and it slightly fluctuated between 0.32 and 0.34 . The consistent content of carotenoids in CHL2220 and its growth performance suggests that this strain was tolerant against the extended tobacco smoke treatment. This might be due to its defense mechanisms against toxic materials. Substantial changes were observed in $\mathrm{CHL}-2221$; prior to the exposure, the $\mathrm{Car} / \mathrm{Chl}$ ratio was 0.28 , while it increased significantly to 0.43 ( $t$-test, $P>0.05$ ) after treatment. The enhanced carotenoid to chlorophyll ratio suggests stress experience upon tobacco smoke exposure. Response to different stress conditions by enhancement of carotenoids was previously confirmed [33]. Specifically, the increased level of carotenoids that have been previously reported in Chlamydomonas experienced heavy metal stress induced by $\mathrm{Cu}, \mathrm{Ag}, \mathrm{Cr}, \mathrm{Cd}$ and $\mathrm{Hg}$ [35]. Increased carotenoid levels have been associated with the increase of ${ }^{1} \mathrm{O}_{2}$ (singlet oxygen), which is known as a reactive $\mathrm{O}_{2}$ species [33], suggesting the possible effect of toxic chemicals found in tobacco smoke.

\subsection{Effect of tobacco smoke on biochemical components}

In general, lipid content of both strains decreased under the presence of tobacco smoke. According to Fig.3a, the lipid content of CHL-2220 was $15.16 \%$ that reduced to $13.82 \%$ under tobacco smoke. The same trend was observed for the CHL-2221 strain as its lipid content decreased from $15.55 \%$ to $13.37 \%$ when growing under tobacco smoke compared to the control. Although the changes were not significant in the CHL-2220 strain, CHL-2221 showed a significant reduction after smoke treatment (Fig.3a), suggesting inhibition of lipid biosynthesis upon exposure to tobacco smoke. Accumulation of carbohydrates in microalgae frequently takes place under stress conditions. Besides, green microalgae tend to store starch as the main carbon and energy storage compound [36,37]. According to Fig.3b, the effect of smoke on carbohydrate content varied between the two strains. The carbohydrate content of CHL-2221 increased significantly under the presence of tobacco smoke, while it remained almost similar to the control in CHL-2220 after smoke exposure. Considering the growth inhibition of CHL-2221 and its carbohydrate accumulation, it can be suggested that this strain accumulates carbohydrates in response to tobacco smoke stress. As carbohydrate metabolism is the crucial player in maintaining the balance of photosynthesis and proliferation. Also, starch is the dominant storage molecule in Chlamydomonas [38], which is synthesized primarily and more intensively than lipids under mild stress conditions, and it is mobilized faster after turning to the normal condition [39]. However, an opposite trend was observed regarding the protein content, which increased in CHL-2220 and CHL-2221 from $30.91 \%$ and $35.48 \%$ to $34.56 \%$ and $36.55 \%$, respectively (Fig.3c). A significant change of protein content was observed in CHL2220, while it was insignificant in CHL-2221. This pattern was expected as CHL-2220 showed tolerance toward tobacco smoke and, therefore, it could synthesize proteins that confer this ability. Heat shock proteins are the common proteins that are usually expressed under stress conditions; however, further molecular studies are required to identify the differentially expressed proteins [40].

\subsection{Effect of tobacco smoke on fatty acid profile}


The fatty acid profile of CHL-2220 and CHL-2221 under both ambient conditions and smoke is presented in Table 2. The response of studied strains was different toward the accumulation of saturated fatty acids (SFAs), where SFAs content of CHL-2220 dropped from $29.15 \%$ to $20.44 \%$. However, no significant changes were observed in SFAs content of CHL-2221, which remained at around $20 \%$. Palmitic acid was the dominant constituent of SFAs, and showed significant changes upon culture treatment by tobacco smoke. It is known that palmitic acid is the most common component of the cell membrane and is the dominant SFAs [41]. Its significant changes in response to salinity stress have been reported previously $[42,43]$, suggesting its possible role in acclimation to stress conditions. Commonly the studied strain showed lower palmitic acid in response to tobacco smoke, decreasing from $20.18 \%$ to $11.22 \%$ in CHL2220 and from $10.78 \%$ to $7.79 \%$ in CHL-2221. In CHL-2220, the stearic acid did not demonstrate significant changes in response to tobacco smoke, while it significantly increased from $4.51 \%$ to $7.64 \%$ in CHL-2221.

Table 2. Comparison of fatty acid methyl esters of CHL-2220 and CHL-2221 under exposure to tobacco smoke and ambient air. The fatty acids with less than $1 \%$ content are not shown in the table.

\begin{tabular}{|c|c|c|c|c|}
\hline \multirow[t]{2}{*}{ FAMEs } & \multicolumn{2}{|l|}{ CHI-2220 } & \multicolumn{2}{|l|}{ CHL-2221 } \\
\hline & Control & Smoke treated & Control & Smoke treated \\
\hline c5 (Valeric Acid) & $4.12 \pm 0.75$ & $5.75 \pm 0.43^{\star}$ & $3.65 \pm 0.67$ & $4.55 \pm 0.62^{\star}$ \\
\hline c16 (Palmitic) & $20.01 \pm 1.48^{*}$ & $11.21 \pm 0.69$ & $10.68 \pm 0.16 *$ & $7.31 \pm 0.42$ \\
\hline C16:1 (Palmitoleic acid) & $4.04 \pm 0.51^{\star}$ & $3.35 \pm 0.44$ & $4.36 \pm 0.97$ & $3.32 \pm 0.17$ \\
\hline c16:2 (Hexadecadienoic acid) & - & $3.42 \pm 0.67^{\star}$ & - & $3.94 \pm 0.17 *$ \\
\hline C16:3 (Palmitolinolenic) & $3.16 \pm 0.46$ & $5.18 \pm 1.42^{\star}$ & $3.48 \pm 0.18$ & $6.02 \pm 0.77^{\star}$ \\
\hline C16:4 (Palmitidonic) & $14.73 \pm 0.16$ & $14.79 \pm 2.27$ & $15.79 \pm 1.06^{*}$ & $10.19 \pm 0.81$ \\
\hline c18 (Stearic) & $4.32 \pm 0.58^{\star}$ & $2.83 \pm 0.60$ & $4.21 \pm 0.54$ & $4.18 \pm 0.56$ \\
\hline c18:1 (Oleic acid) & $7.50 \pm 0.43$ & $8.25 \pm 0.79$ & $8.11 \pm 0.98$ & $17.30 \pm 0.17 *$ \\
\hline C18:2 (Linoleic acid) & $10.12 \pm 0.37 *$ & $7.66 \pm 0.86$ & $9.81 \pm 1.00^{*}$ & $7.74 \pm 0.45$ \\
\hline C18:3 (Alpha-linolenic acid) & $29.97 \pm 1.29$ & $30.10 \pm 5.78$ & $29.72 \pm 0.94^{*}$ & $21.00 \pm 1.27$ \\
\hline c19:3 (Nonadecatrienoic Acid) & $0.23 \pm 0.02 *$ & - & $4.76 \pm 0.55^{\star}$ & - \\
\hline c20:3 (dihomo-y-linolenic acid) & - & $5.67 \pm 1.18^{\star}$ & - & $8.38 \pm 1.33^{\star}$ \\
\hline c22:3 (Docosatrienoic acid) & - & - & - & $3.28 \pm 0.69 *$ \\
\hline Q SFAs & $29.25 \pm 1.38 *$ & $24.14 \pm 1.94$ & $21.21 \pm 1.75^{\star}$ & $18.34 \pm 0.93$ \\
\hline \MUFAs & $11.59 \pm 0.66$ & $15.97 \pm 1.63^{*}$ & $13.10 \pm 0.70$ & $20.73 \pm 0.32 *$ \\
\hline Q PUFAs & $59.16 \pm 1.90$ & $59.88 \pm 3.44$ & $65.69 \pm 1.77 *$ & $60.93 \pm 1.24$ \\
\hline
\end{tabular}


Values are the mean $\pm S D$ of three replicates, while the " $\star$ " denotes to significant difference $(P<0.05)$ with the corresponding control.

MUFAs content significantly affected CHL-2220 and increased from $12.46 \%$ to $20.93 \%$, while it remained almost unchanged to around $112 \%$ in response to tobacco smoke in CHL-2221. Mutually in both strains, palmitoleic acid and oleic acid were the dominant MUFAs. The proportion of palmitoleic acid did not exhibit significant changes between strains and also in response to tobacco exposure. Although oleic acid content showed no significant changes in CHL-2220, it significantly elevated from $7.64 \%$ to $17.09 \%$ in CHL-2221. This suggests the accumulation of TAG as oleic acid as it is one of the major constituents of triacylglycerols (TAGs) [44]. Also, an increased level of oleic acid in response to salinity stress was detected in green microalgae [45].

PUFAs were the main components of FAMEs in the studied strains under smoke and control conditions. In CHL-2220, PUFAs content significantly increased in response to tobacco exposure from $59.49 \%$ to $66.88 \%$. In CHL-2220, the increase of PUFAs content was attributed to the accumulation of C16:2 and C20:3 upon tobacco smoke exposure. However, CHL-2221 preserved almost the same content of PUFAs to around $62 \%$. The most abundant PUFA in both strains was alpha-linolenic acid (C18:3), which is known as the dominant unsaturated fatty acid in many microalgae [46]. Alpha-linolenic acid content under ambient conditions were $29.79 \%$ and $31.20 \%$ in CHL-2220 and CHL-2221, which altered under the presence of smoke to $30.21 \%$ and $22.11 \%$, respectively. The elevated alpha-linolenic acid has been reported in Chlamydomonas strain experiencing stress of phosphorous [47] and nitrogen [48] limitation. Interestingly, hexadecadienoic acid (C16:2) was not detected commonly in both strains under ambient conditions, while upon exposure to tobacco smoke, CHL-2220 and CHL-2221 accumulated $\mathrm{C} 16: 2$ by $3.88 \%$ and $3.81 \%$, respectively. Similarly, dihomo-y-linolenic acid (C20:3) was not detected under aeration by smoke-free air; however, CHL-2220 and CHL-2221 upon exposure to tobacco smoke accumulated this fatty acid by $4.87 \%$ and $8.22 \%$, respectively. It can be seen that exposure of studied strains to tobacco smoke provoked the synthesis of omega- 3 and omega- 6 fatty acids, which play an essential role in human health. Further molecular studies and toxic screening procedures are required before applying the lipid extract of these microalgae as a food supplement. However, by further study, the active compounds triggering the synthesis of omega-3 and omega- 6 fatty acid can be identified for future applications.

\subsection{Effect of tobacco smoke on biodiesel characteristics}

To investigate the effect of tobacco smoke on biodiesel quality, some of the critical fuel properties such CN, IV, SV and DU were evaluated for both strains (Table 3). The DU designates the total mass proportion of mono- and polyunsaturated acids; thus, higher DU means higher unsaturation of fatty acids. The DU changes were not considerably different between the control and treated samples of CHL-2221. While, for CHL-2220 slight increase in the sample treated with tobacco smoke was detected, which showed a rise from 130.10 to 134.37 . The level of DU significantly affects the $\mathrm{CN}$, which indicates the ignition quality of the fuels. The studied strains exhibited relatively low $\mathrm{CN}$ value, and tobacco smoke treatment introduced dissimilar changes to the studied strains. In CHL-2220, the CN value decreased from 30.04 to 25.77 upon 
exposure to tobacco smoke. In contrast, in CHL-2221, the $\mathrm{CN}$ value raised from 26.15 to 29.20 after the treatment. Fuels with low $\mathrm{CN}$ tend to increase gaseous and particulate exhaust emissions, including unburned hydrocarbons ( $\mathrm{HCs}$ ), $\mathrm{SO}_{x}, \mathrm{NO}_{\mathrm{x}}$ and $\mathrm{CO}$, due to incomplete combustion [28]. However, fuels with greater $\mathrm{CN}$ exhibit better combustion, lower emissions, smother start-up, and less knocking of engines [49]. Higher $\mathrm{CN}$ can be achieved if the biodiesel contains fatty acids with lesser hydrocarbon branches and longer fatty acids length [50].

Table 3. Comparison of biodiesel characteristics of two strains of CHL-2220 and CHL-2221 under exposure to smoke and without it.

$\begin{array}{llll}\text { Biodiesel parameters } \quad \text { CHL-2220 Biodiesel } & \text { CHL-2221 }\end{array}$ standard

Control $\begin{gathered}\text { Smoke } \\ \text { treated }\end{gathered} \quad \begin{aligned} & \text { Smoke } \\ & \text { treated }\end{aligned}$

\begin{tabular}{|c|c|c|c|c|c|}
\hline $\begin{array}{l}\text { Degree of unsaturation } \\
\text { (\% wt) }\end{array}$ & $129.91 \pm 3.25$ & $135.74 \pm 5.33$ & $144.48 \pm 3.45$ & $142.60 \pm 2.17$ & - \\
\hline Cetane number (CN) & $30.34 \pm 1.32^{\star}$ & $25.28 \pm 1.55$ & $26.07 \pm 0.78$ & $29.73 \pm 0.58^{*}$ & $\geq 51$ \\
\hline $\begin{array}{l}\text { lodine value (IV, g } \\
\left.\mathrm{l}_{2} / 100 \mathrm{~g}\right)\end{array}$ & $180.34 \pm 4.96$ & $201.73 \pm 7.63^{\star}$ & $199.81 \pm 4.88^{*}$ & $184.53 \pm 3.57$ & $\leq 120$ \\
\hline
\end{tabular}

$\begin{array}{llllll}\text { Saponification value } & 221.72 \pm 2.61 & 223.94 \pm 1.48 & 220.73 \pm 2.86 & 218.79 \pm 2.25 & - \\ \text { (SV) }\end{array}$

\begin{tabular}{lllll}
\hline $\begin{array}{l}\text { Long chain saturation } \\
\text { factor (LCSF) }\end{array}$ & $4.16 \pm 0.38 *$ & $2.78 \pm 0.35$ & $3.32 \pm 0.17$ & $3.35 \pm 0.39 *$
\end{tabular}

\begin{tabular}{llllll|}
$\begin{array}{l}\text { Cold filter plugging } \\
\left.\text { point (CFPP, }{ }^{\circ} \mathrm{C}\right)\end{array}$ & $-3.41 \pm 1.19$ & $-7.75 \pm 1.10^{*}$ & $-6.05 \pm 0.54^{*}$ & $-5.94 \pm 1.21$ & - \\
\hline HHV $\left(\mathrm{MJ} \mathrm{kg}^{-1}\right)$ & $37.63 \pm 0.16^{*}$ & $37.22 \pm 0.05$ & $37.38 \pm 0.05$ & $37.69 \pm 0.05^{\star}$ & 37 \\
\hline Reference & This study & This study & This study & This study & $\begin{array}{l}\text { (EN } \\
14214, \\
\end{array}$ \\
& & & & $2008)$
\end{tabular}

Values are the mean \pm SD of three replicates, while the " $*$ " denotes to significant difference $(P<0.05)$ with the corresponding control.

lodine value (IV) is another measurement of the unsaturation within the mixture of fatty acids, which represents the grams of iodine that react with $100 \mathrm{~g}$ of FAME sample [51]. IV indicates that the unsaturated fatty acids in biodiesel rise with the double bond numbers in the fatty acid chain. The upper limit of IV suggested by the European standard is 120 [52]. The IV value of the CHL-2220 increased by exposure of tobacco smoke from 180.51 to $199.65 \mathrm{~g} \mathrm{I}_{2} 100 \mathrm{~g}^{-1}$. While the IV value in CHL-2221 dropped from 198.21 to $188.22 \mathrm{I}_{2} 100 \mathrm{~g}^{-1}$. In biodiesel, IV above $120 \mathrm{~g} \mathrm{I}_{2} 100 \mathrm{~g}^{-1}$ leads the PUFAs to become polymerized and form glycerides at high temperatures, which consequently cause the generation of 
deposits or deterioration of the lubricating oil [53]. Saponification value (SV) signifies the milligrams of potassium hydroxide $(\mathrm{KOH})$ needed to saponify $1 \mathrm{~g}$ of FAMEs. SV has a negative correlation with the FA chain length. In this study, SV value was commonly beyond the European Standards (EN 14214) limit. The SV value of CHL-2220 was almost unchanged and remained around 224 after culture treatment with tobacco smoke. A slight decrease was observed in the SV value of CHL-2221 after the treatment, where the SV value declined from 221.84 to 216.19 . It is known that the high SV requires extra methanol, and produces added glycerol but a reduced amount of biodiesel [54].

The CFPP of biodiesel indicates the minimum temperature that the fuel can provide trouble-free run in the systems [55]. The CFPP value rises substantially with the concentration of SFA in biodiesel. There was a slight decrease in CFPP of both studied strains in response to tobacco smoke. In CHL-2220, it slightly decreased from $-4.28{ }^{\circ} \mathrm{C}$ to $-6.89{ }^{\circ} \mathrm{C}$, and in $\mathrm{CHL}-2221$, it declined from $-5.99^{\circ} \mathrm{C}$ to $-7.28^{\circ} \mathrm{C}$. It indicates that tobacco smoke introduced a positive impact on the studied strains. At the same time, temperature limits can be specified by each country individually for different periods of the year depending on the climate conditions. The long-chain saturation factor (LCSF) is an essential parameter controlling cetane number and IV of biodiesel, where high LCSF is desirable physicochemical properties of the produced biodiesel. In contrast, the longer the biodiesel carbon chains, the worse are their low-temperature properties [53]. In this experiment, the LCSF value was reduced in both strains by exposing cultures to tobacco smoke. In CHL2220, it declined from 3.89 to 3.04 , and in CHL-2221, it declined from 3.33 to 2.92. Higher heating value $(\mathrm{HHV})$ is the volume of energy generated by the thorough combustion of a fuel or material. It is calculated in units of energy per volume of fuel [56]. It is known that the fuels with greater HHV are more competent for small-size engines [57]. The studied strains commonly exhibited the HHV values around 37, which is in the acceptable range suggested by EN [52].

The relatively higher SV value of the present strains suggests potentially a lower yield of biodiesel. Also, according to European standards (EN14214) and Australian standards for minimum CN value are 51 [52], [58]; the studied strain could not meet the standard $\mathrm{CN}$ values for biodiesel quality due to high DU value. Overall, the current results conclude that the DU of this strain should be decreased if it is selected to be used for biodiesel production. However, a single FAMEs cannot fulfill all the properties of ideal biodiesel. A proportionate balance between a higher amount of MUFAs such as oleic acid, and fewer SFAs and PUFAs would suffice the purpose. One solution can be blending microalgal biomass with other feedstocks to upgrade the quality [14]. The ester profile of the studied Chlamydomonas strains showed relatively high concentrations of PUFAs to beyond $60 \%$ due to a high proportion of palmitolinolenic, palmitidonic, linoleic acid and alpha-linolenic acid. On the other hand, the fatty acid profile demonstrated pharmacological potential for therapy or diet, as some of the key components such as linoleic acid and alpha-linolenic acid, are reported as bioactive metabolites [59].

\section{Conclusion}

The growth and biochemical properties of two Chlamydomonas strains in response to tobacco smoke exposure were studied. It was shown that the effect of tobacco smoke is strain-dependent as CHL-2220 
was able to tolerate introduced tobacco smoke. However, the growth, pigments, and biochemical composition of $\mathrm{CHL}-2221$ were severely affected. The present study suggests the possible application of microalgae as a promising air purifier to enhance the $\mathrm{O}_{2}$ level of the area with tobacco smoke. Mutually, both strains' lipid extracts demonstrated poor characteristics for biodiesel production, while considerable PUFAs proportion suggested its applicability for pharmaceuticals and nutrients food for animals.

\section{Declarations}

\section{Funding}

This work was supported by China Postdoctoral Science Foundation funded (2019M661742).

\section{Conflicts of interest/Competing interests}

There is no confilict of interest to declear.

\section{Availability of data and material}

The raw data supporting the conclusions of this article will be made available by the authors, without undue reservation.

\section{Code availability}

Not applicable.

\section{Ethics approval}

Not applicable.

\section{Consent to participate}

Not applicable.

\section{Consent for publication}

Not applicable.

\section{References}

1. W. Health Organization, Ambient air pollution: a global assessment of exposure and burden of disease, Clean Air J. 26 (2016) 6. https://doi.org/10.17159/2410-972x/2016/v26n2a4.

2. J. González-Martín, N.J.R. Kraakman, C. Pérez, R. Lebrero, R. Muñoz, A state-of-the-art review on indoor air pollution and strategies for indoor air pollution control, Chemosphere. 262 (2021). https://doi.org/10.1016/j.chemosphere.2020.128376. 
3. L. Deng, Q. Deng, The basic roles of indoor plants in human health and comfort, Environ. Sci. Pollut. Res. 25 (2018) 36087-36101. https://doi.org/10.1007/s11356-018-3554-1.

4. K. Azuma, N. Kagi, U. Yanagi, H. Osawa, Effects of low-level inhalation exposure to carbon dioxide in indoor environments: A short review on human health and psychomotor performance, Environ. Int. 121 (2018) 51-56. https://doi.org/10.1016/j.envint.2018.08.059.

5. B. Du, M.C. Tandoc, M.L. Mack, J.A. Siegel, Indoor $\mathrm{CO}_{2}$ concentrations and cognitive function: A critical review, 2020. https://doi.org/10.1111/ina.12706.

6. J. Cheng, Y. Zhu, Z. Zhang, W. Yang, Modification and improvement of microalgae strains for strengthening $\mathrm{CO}_{2}$ fixation from coal-fired flue gas in power plants, Bioresour. Technol. 291 (2019) 121850. https://doi.org/10.1016/j.biortech.2019.121850.

7. N.A. Megahed, E.M. Ghoneim, Indoor Air Quality: Rethinking rules of building design strategies in post-pandemic architecture, Environ. Res. (2020) 110471. https://doi.org/10.1016/j.envres.2020.110471.

8. Q. Lu, C. Ji, Y. Yan, Y. Xiao, J. Li, L. Leng, W. Zhou, Application of a novel microalgae-film based air purifier to improve air quality through oxygen production and fine particulates removal, J. Chem. Technol. Biotechnol. 94 (2019) 1057-1063. https://doi.org/10.1002/jctb.5852.

9. I. Durán, F. Rubiera, C. Pevida, Microalgae: Potential precursors of $\mathrm{CO}_{2}$ adsorbents, J. $\mathrm{CO}_{2}$ Util. 26 (2018) 454-464. https://doi.org/10.1016/j.jcou.2018.06.001.

10. H. Chowdhury, B. Loganathan, Third-generation biofuels from microalgae: a review, Curr. Opin. Green Sustain. Chem. 20 (2019) 39-44. https://doi.org/10.1016/j.cogsc.2019.09.003.

11. S. Wang, B.B. Uzoejinwa, A.E.F. Abomohra, Q. Wang, Z. He, Y. Feng, B. Zhang, C.W. Hui, Characterization and pyrolysis behavior of the green microalga Micractinium conductrix grown in lab-scale tubular photobioreactor using Py-GC/MS and TGA/MS, J. Anal. Appl. Pyrolysis. 135 (2018) 340-349. https://doi.org/10.1016/j.jaap.2018.08.019.

12. P.A. Owusu, S. Asumadu-Sarkodie, A review of renewable energy sources, sustainability issues and climate change mitigation, Cogent Eng. 3 (2016). https://doi.org/10.1080/23311916.2016.1167990.

13. S. Bellou, M.N. Baeshen, A.M. Elazzazy, D. Aggeli, F. Sayegh, G. Aggelis, Microalgal lipids biochemistry and biotechnological perspectives, Biotechnol. Adv. 32 (2014) 1476-1493. https://doi.org/10.1016/j.biotechadv.2014.10.003.

14. A.E.F. Abomohra, M. Elsayed, S. Esakkimuthu, M. El-Sheekh, D. Hanelt, Potential of fat, oil and grease (FOG) for biodiesel production: A critical review on the recent progress and future perspectives, Prog. Energy Combust. Sci. 81 (2020) 100868. https://doi.org/10.1016/j.pecs.2020.100868.

15. M. Veillette, A. Giroir-Fendler, N. Faucheux, M. Heitz, Biodiesel from microalgae lipids: from inorganic carbon to energy production, Biofuels. 9 (2018) 175-202. https://doi.org/10.1080/17597269.2017.1289667.

16. O. Promoters, O. Fermentation, M. Puri, T. Thyagarajan, A. Gupta, C.J. Barrow, Omega-3 Fatty Acids Produced from Microalgae, (2014) 1-15. 
17. V. Kiron, W. Phromkunthong, M. Huntley, I. Archibald, G. De Scheemaker, Marine microalgae from biorefinery as a potential feed protein source for Atlantic salmon, common carp and whiteleg shrimp, Aquac. Nutr. 18 (2012) 521-531. https://doi.org/10.1111/j.1365-2095.2011.00923.x.

18. N. Renuka, A. Guldhe, R. Prasanna, P. Singh, F. Bux, Microalgae as multi-functional options in modern agriculture: current trends, prospects and challenges, Biotechnol. Adv. 36 (2018) 1255-1273. https://doi.org/10.1016/j.biotechadv.2018.04.004.

19. M.I. Gilmour, M.S. Jaakkola, S.J. London, A.E. Nel, C.A. Rogers, How exposure to environmental tobacco smoke, outdoor air pollutants, and increased pollen burdens influences the incidence of asthma, Environ. Health Perspect. 114 (2006) 627-633. https://doi.org/10.1289/ehp.8380.

20. S. Van Den Hende, H. Vervaeren, N. Boon, Flue gas compounds and microalgae: (Bio-)chemical interactions leading to biotechnological opportunities, Biotechnol. Adv. 30 (2012) 1405-1424. https://doi.org/10.1016/j.biotechadv.2012.02.015.

21. M. Pion, M.S. Givel, Airport smoking rooms don't work, Tob. Control. 13 (2004) 37-40. https://doi.org/10.1136/tc.2003.005447.

22. M.A. Scranton, J.T. Ostrand, F.J. Fields, S.P. Mayfield, Chlamydomonas as a model for biofuels and bio-products production, Plant J. 82 (2015) 523-531. https://doi.org/10.1111/tpj.12780.

23. B. Barati, P.E. Lim, S.Y. Gan, S.W. Poong, S.M. Phang, J. Beardall, Effect of elevated temperature on the physiological responses of marine Chlorella strains from different latitudes, J. Appl. Phycol. 30 (2018). https://doi.org/10.1007/s10811-017-1198-z.

24. A.E.F. Abomohra, M. Wagner, M. El-Sheekh, D. Hanelt, Lipid and total fatty acid productivity in photoautotrophic fresh water microalgae: Screening studies towards biodiesel production, J. Appl. Phycol. 25 (2013) 931-936. https://doi.org/10.1007/s10811-012-9917-y.

25. H.K. Lichtenthaler, Chlorophylls and Carotenoids: Pigments of Photosynthetic Biomembranes, Methods Enzymol. 148 (1987) 350-382. https://doi.org/10.1016/0076-6879(87)48036-1.

26. M.A. Borowitzka, N.R. Moheimani, Standard Methods for Measuring Growth of Algae and Their Composition, Algae for Biofuels and Energy. (2013). https://doi.org/10.1007/978-94-007-5479-9.

27. E.G. Bligh, W.J. Dyer, A rapid method of total lipid extraction and purification, Can. J. Biochem. Physiol. 37 (1959) 911-917.

28. L.F. Ramírez-Verduzco, J.E. Rodríguez-Rodríguez, A.D.R. Jaramillo-Jacob, Predicting cetane number, kinematic viscosity, density and higher heating value of biodiesel from its fatty acid methyl ester composition, Fuel. 91 (2012) 102-111. https://doi.org/10.1016/j.fuel.2011.06.070.

29. M. Ashour, M.E. Elshobary, R. El-Shenody, A.W. Kamil, A.E.F. Abomohra, Evaluation of a native oleaginous marine microalga Nannochloropsis oceanica for dual use in biodiesel production and aquaculture feed, Biomass and Bioenergy. 120 (2019) 439-447. https://doi.org/10.1016/j.biombioe.2018.12.009.

30. A. Patel, N. Arora, J. Mehtani, V. Pruthi, P.A. Pruthi, Assessment of fuel properties on the basis of fatty acid profiles of oleaginous yeast for potential biodiesel production, Renew. Sustain. Energy Rev. 77 (2017) 604-616. https://doi.org/10.1016/j.rser.2017.04.016. 
31. J.M. da Silva, Monitoring Photosynthesis by In Vivo Chlorophyll Fluorescence: Application to HighThroughput Plant Phenotyping, Appl. Photosynth. - New Prog. (2016) 3-22. https://doi.org/10.5772/62391.

32. T.C. Haire, C. Bell, K. Cutshaw, B. Swiger, K. Winkelmann, A.G. Palmer, Robust Microplate-Based Methods for Culturing and in Vivo Phenotypic Screening of Chlamydomonas reinhardtii, Front. Plant Sci. 9 (2018) 1-10. https://doi.org/10.3389/fpls.2018.00235.

33. J.Q.M. Almarashi, S.E. El-Zohary, M.A. Ellabban, A.E.F. Abomohra, Enhancement of lipid production and energy recovery from the green microalga Chlorella vulgaris by inoculum pretreatment with lowdose cold atmospheric pressure plasma (CAPP), Energy Convers. Manag. 204 (2020). https://doi.org/10.1016/j.enconman.2019.112314.

34. A.E.-F. Abomohra, A.H. El-Naggar, S.O. Alaswad, M. Elsayed, M. Li, W. Li, Enhancement of biodiesel yield from a halophilic green microalga isolated under extreme hypersaline conditions through stepwise salinity adaptation strategy, Bioresour. Technol. 310 (2020) 123462. https://doi.org/10.1016/j.biortech.2020.123462.

35. B. Nowicka, B. Pluciński, P. Kuczyńska, J. Kruk, Physiological characterization of Chlamydomonas reinhardtii acclimated to chronic stress induced by $\mathrm{Ag}, \mathrm{Cd}, \mathrm{Cr}, \mathrm{Cu}$ and $\mathrm{Hg}$ ions, Ecotoxicol. Environ. Saf. 130 (2016) 133-145. https://doi.org/10.1016/j.ecoenv.2016.04.010.

36. S. Zhu, Y. Wang, W. Huang, J. Xu, Z. Wang, J. Xu, Z. Yuan, Enhanced Accumulation of Carbohydrate and Starch in Chlorella zofingiensis Induced by Nitrogen Starvation, Appl. Biochem. Biotechnol. 174 (2014) 2435-2445. https://doi.org/10.1007/s12010-014-1183-9.

37. A.E.F. Abomohra, H. Shang, M. El-Sheekh, H. Eladel, R. Ebaid, S. Wang, Q. Wang, Night illumination using monochromatic light-emitting diodes for enhanced microalgal growth and biodiesel production, Bioresour. Technol. 288 (2019) 121514. https://doi.org/10.1016/j.biortech.2019.121514.

38. R. Puzanskiy, E. Tarakhovskaya, A. Shavarda, M. Shishova, Metabolomic and physiological changes of Chlamydomonas reinhardtii (Chlorophyceae, Chlorophyta) during batch culture development, J. Appl. Phycol. 30 (2018) 803-818. https://doi.org/10.1007/s10811-017-1326-9.

39. M. Siaut, S. Cuiné, C. Cagnon, B. Fessler, M. Nguyen, P. Carrier, A. Beyly, F. Beisson, C. Triantaphylidès, Y. Li-Beisson, G. Peltier, Oil accumulation in the model green alga Chlamydomonas reinhardtii: characterization, variability between common laboratory strains and relationship with starch reserves., BMC Biotechnol. 11 (2011) 7. https://doi.org/10.1186/1472-6750-11-7.

40. B. Barati, S.-Y. Gan, P.-E. Lim, J. Beardall, S.-M. Phang, Green algal molecular responses to temperature stress, Acta Physiol. Plant. 41 (2019) 26. https://doi.org/10.1007/s11738-019-2813-1.

41. H. Osorio, C. Jara, K. Fuenzalida, E. Rey-Jurado, M. Vásquez, High-efficiency nuclear transformation of the microalgae Nannochloropsis oceanica using Tn5 Transposome for the generation of altered lipid accumulation phenotypes, Biotechnol. Biofuels. 12 (2019) 134. https://doi.org/10.1186/s13068-019-1475-y.

42. M. An, S. Mou, X. Zhang, Z. Zheng, N. Ye, D. Wang, W. Zhang, J. Miao, Expression of fatty acid desaturase genes and fatty acid accumulation in Chlamydomonas sp. ICE-L under salt stress, 
Bioresour. Technol. 149 (2013) 77-83. https://doi.org/10.1016/j.biortech.2013.09.027.

43. L. Yang, J. Chen, S. Qin, M. Zeng, Y. Jiang, L. Hu, P. Xiao, W. Hao, Z. Hu, A. Lei, J. Wang, Growth and lipid accumulation by different nutrients in the microalga Chlamydomonas reinhardtii, Biotechnol. Biofuels. 11 (2018) 1-12. https://doi.org/10.1186/s13068-018-1041-z.

44. L. de Jaeger, J. Springer, E.J.H. Wolbert, D.E. Martens, G. Eggink, R.H. Wijffels, Gene silencing of stearoyl-ACP desaturase enhances the stearic acid content in Chlamydomonas reinhardtii, Bioresour. Technol. 245 (2017) 1616-1626. https://doi.org/10.1016/j.biortech.2017.06.128.

45. G. Srivastava, Nishchal, V. V. Goud, Salinity induced lipid production in microalgae and cluster analysis (ICCB 16-BR_047), Elsevier Ltd, 2017. https://doi.org/10.1016/j.biortech.2017.03.175.

46. M. Moon, C.W. Kim, W.K. Park, G. Yoo, Y.E. Choi, J.W. Yang, Mixotrophic growth with acetate or volatile fatty acids maximizes growth and lipid production in Chlamydomonas reinhardtii, Algal Res. 2 (2013) 352-357. https://doi.org/10.1016/j.algal.2013.09.003.

47. H.A. Qari, M. Oves, Fatty acid synthesis by Chlamydomonas reinhardtii in phosphorus limitation, J. Bioenerg. Biomembr. 52 (2020) 27-38. https://doi.org/10.1007/s10863-019-09813-8.

48. H. Sun, X. Mao, T. Wu, Y. Ren, F. Chen, B. Liu, Novel insight of carotenoid and lipid biosynthesis and their roles in storage carbon metabolism in Chlamydomonas reinhardtii, Bioresour. Technol. 263 (2018) 450-457. https://doi.org/10.1016/j.biortech.2018.05.035.

49. G. Knothe, L.F. Razon, Biodiesel fuels, Prog. Energy Combust. Sci. 58 (2017) 36-59. https://doi.org/10.1016/j.pecs.2016.08.001.

50. G. Knothe, Fuel properties of highly polyunsaturated fatty acid methyl esters. Prediction of fuel properties of algal biodiesel, Energy and Fuels. 26 (2012) 5265-5273. https://doi.org/10.1021/ef300700v.

51. M.J. Ramos, C.M. Fernández, A. Casas, L. Rodríguez, Á. Pérez, Influence of fatty acid composition of raw materials on biodiesel properties, Bioresour. Technol. 100 (2009) 261-268. https://doi.org/10.1016/j.biortech.2008.06.039.

52. EN 14214, Automotive fuels - Fatty acid methyl esters (FAME) for diesel engines - Requirements and test methods, Eur Comm Stand. (2008) EN14214. https://doi.org/ISBN 9780580707810.

53. N.A. Shaltout, M.A. Ghazal, N.G. Shams El-Din, A.E. Ali, D.M. Beltagy, Optimization and kinetic studies of biodiesel production from the green alga Ulva fasciata delile, Egypt. J. Aquat. Biol. Fish. 23 (2019) 301-322. https://doi.org/10.21608/ejabf.2019.54922.

54. J.C.J. Bart, N. Palmeri, S. Cavallaro, Emerging new energy crops for biodiesel production, Biodiesel Sci. Technol. (2010) 226-284. https://doi.org/10.1533/9781845697761.226.

55. S. Vidyashankar, K.S. VenuGopal, G.V. Swarnalatha, M.D. Kavitha, V.S. Chauhan, R. Ravi, A.K. Bansal, R. Singh, A. Pande, G.A. Ravishankar, R. Sarada, Characterization of fatty acids and hydrocarbons of chlorophycean microalgae towards their use as biofuel source, Biomass and Bioenergy. 77 (2015) 75-91. https://doi.org/10.1016/j.biombioe.2015.03.001.

56. A. Demirbas, Calculation of higher heating values of fatty acids, Energy Sources, Part A Recover. Util. Environ. Eff. 38 (2016) 2693-2697. https://doi.org/10.1080/15567036.2015.1115924. 
57. M. Mondal, A.A. Khan, G. Halder, Estimation of biodiesel properties based on fatty acid profiles of Chlamydomonas sp. BTA 9032 and Chlorella sp. BTA 9031 obtained under mixotrophic cultivation conditions, Biofuels. 0 (2019) 1-7. https://doi.org/10.1080/17597269.2019.1600453.

58. D.A. Kemp, D. Kemp, Fuel Standard (Biodiesel) Determination, (2003) 2003-2005.

59. Scott D. Doughman, Srirama Krupanidhi, Carani B. Sanjeevi, Omega-3 Fatty Acids for Nutrition and Medicine: Considering Microalgae Oil as a Vegetarian Source of EPA and DHA, Curr. Diabetes Rev. 3 (2007) 198-203. https://doi.org/10.2174/157339907781368968.

\section{Figures}



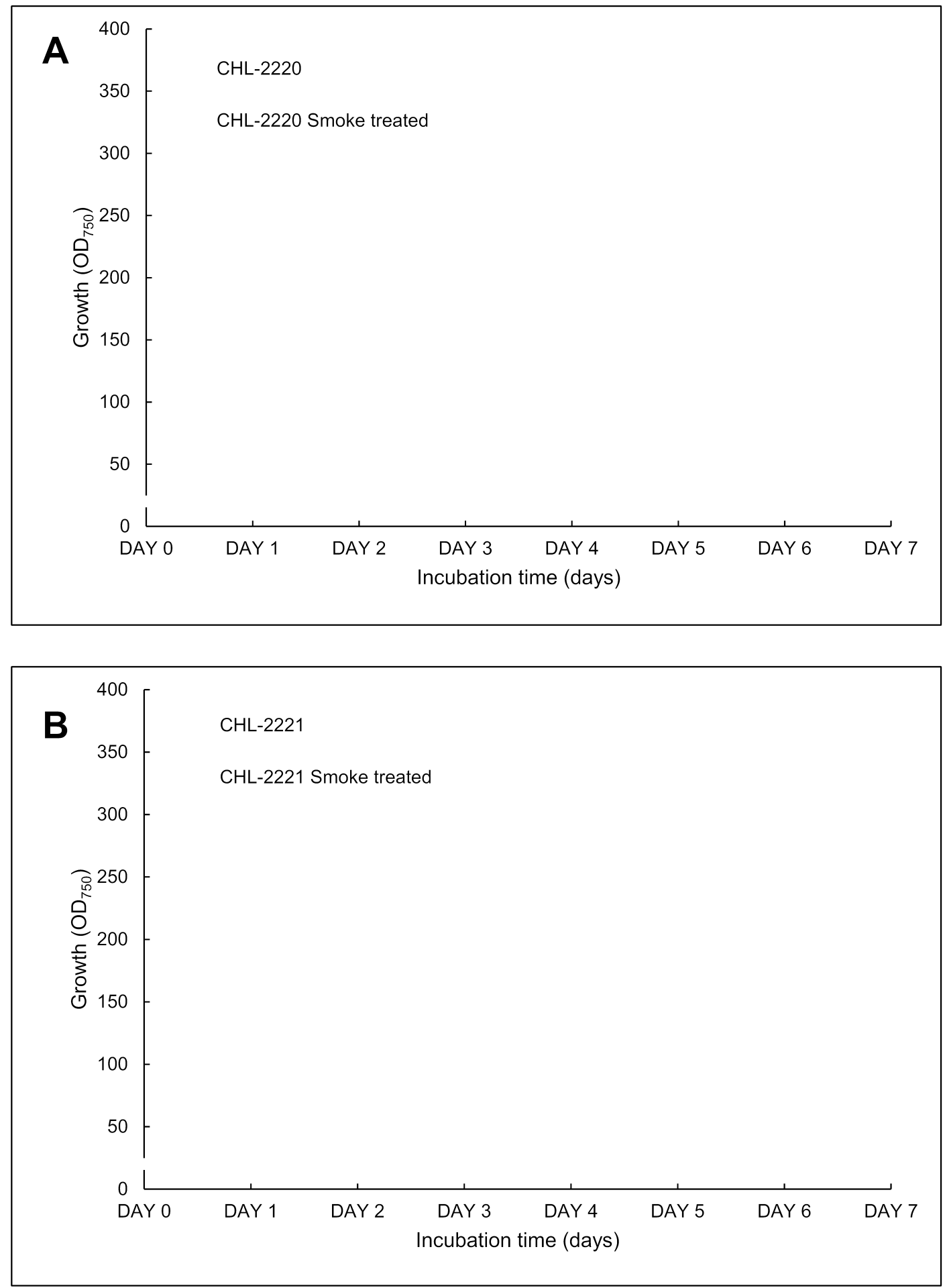

\section{Figure 1}

Comparison of growth of the two strains of CHL-2220 (A) and CHL-2221 (B) under exposure to smoke and ambient conditions. Data signify the mean value of triplicates and error bars are standard deviations. 


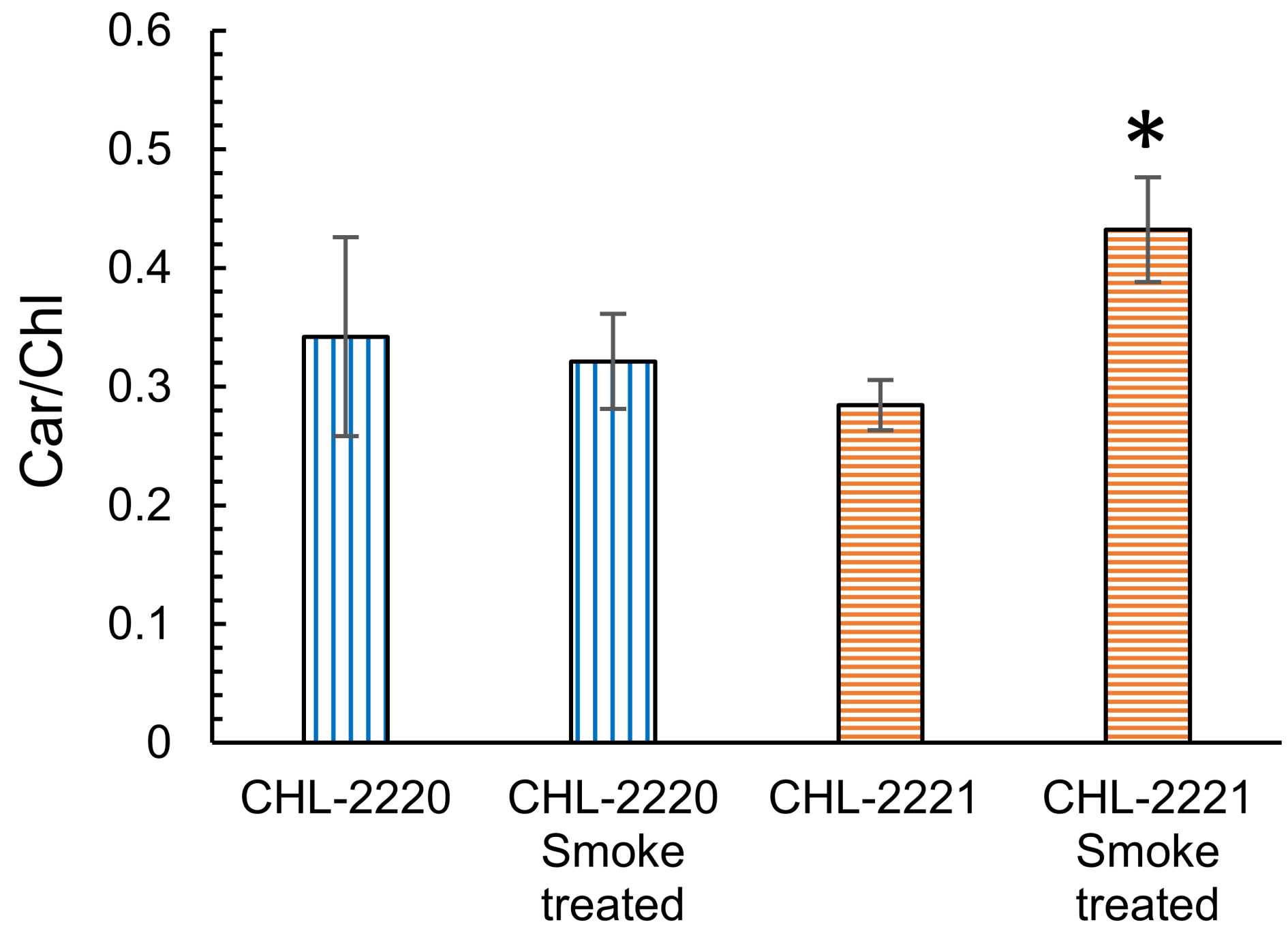

Figure 2

Comparison carotenoid to chlorophyll ratio of two strains of CHL-2220 and CHL-2221 under seven days of exposure to smoke comparing to the ambient air. Data signify the mean value of triplicates and error bars are standard deviations. $\left.{ }^{*}\right)$ Indicates a significant difference $(P<0.05)$ between the treated cultures and the control. 

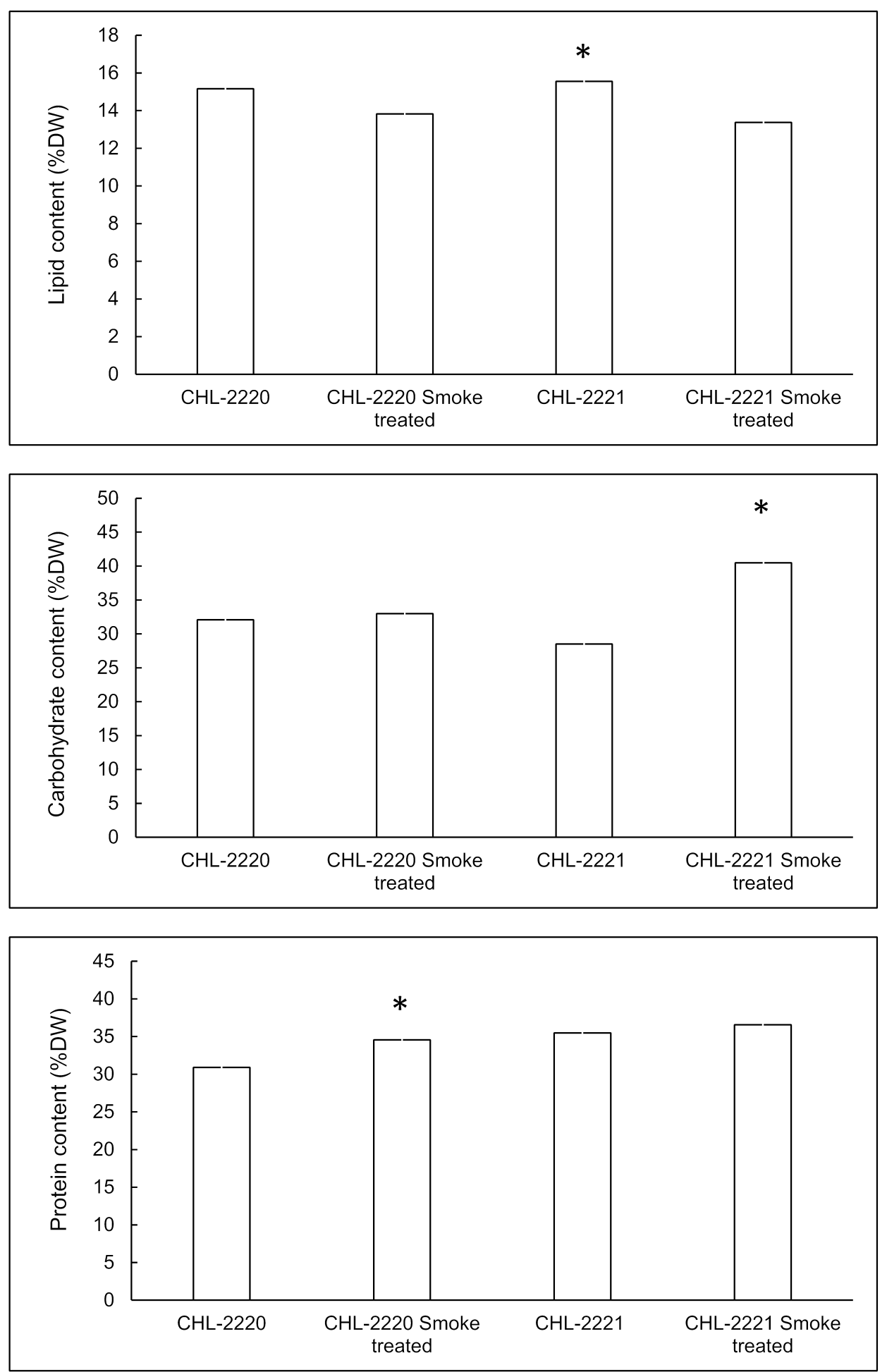

\section{Figure 3}

Biochemical compositions of CHL-2220 and CHL-2221 upon seven days exposure to tobacco smoke and ambient air. Data signify the mean value of triplicates and error bars are standard deviations. $\left(^{*}\right)$ Indicates a significant difference $(P<0.05)$ between treated cultures and the control. 